THURSDAY, NOVEMBER 14,1878

\section{CLEOPATRA'S NEEDLE AND THE WIND PRESSURE}

$T H E$ statements recently made in the Times respecting

the stability of Cleopatra's needle and the maximum intensity of the pressure of the wind in this country have awakened much interest, if not anxiety, about the subject. The appearance of the lofty obelisk balanced on so small a base suggests to many the thought of an egg standing on its end, and presents every idea of instability. This idea is much amplified by a very erroneous estimation, we believe, by most persons of the real dimensions of the base; we have heard this estimated at various diameters down to two feet, but in reality it is in no direction less than five. The statement that the stability of the obelisk is sufficient to withstand a wind pressure of 80 or $90 \mathrm{lbs}$. per square foot having been made, the storm from Liverpool at once broke on it and upset people's minds, if not the monolith. Thus we learn, from the observations taken by Mr. Hartnup, the astronomer at the Liverpool Observatory, that on January 30, 1868 , "it began to blow strongly about 9 A.M., and from that time gradually increased in violence until halfpast II P.M. On the 3rst, when there was one gust of wind which registered $5 \mathrm{r}$ lbs. an the square foot. From this time the gale rapidly increased till noon next day, blowing with a severity quite unprecedented in this colintry. The anemometer which has been erected at the Bidston Observatory is made to register up to 60 los. on the square foot, the idea being that no gale would reach that degree of violence. Between eleven o'clock and one o'clock, however, the registering pencil was driven far beyond this limit, and Mr. Hartnup calculated that at several periods the pressure could not have been less than from $70 \mathrm{lbs}$. to $80 \mathrm{lbs}$, on the square foot. The anemometer was erected in 1851 , and the most severe gale registered up to this time was in December, 1863 , when there were three gusts which registered 45 lbs. to the square foot." Further details respecting this remarkable burricane will be found in the foumal of the Scottish Meteorological Society, from which we find that at Glasgow, from I. 15 P.M. to I.3O P.M., twenty-one miles of wind passed the observatory, giving a velocity of eighty-four miles per hour, or corresponding to a pressure of $35 \frac{1}{2} \mathrm{lbs}$. to the square foot, while the strongest gusts registered $42 \mathrm{lbs}$. on the square foot. At Edinburgh the gale was more severe than at the latter place; cabs and horses are said to have been blown over, but there is no record of the pressure or velocity as there was unfortunately no anemometer in working order. Many authorities state that the maximum pressure of the wind does not exceed 55 lbs, to the square foot in this country, and as this is the figure commonly assumed by engineers in the design of large structures, it is of the greatest importance that the trustworthiness of the Bidston anemometers should be ascertained. Pressure anemometers are obviously liable to errors from the varying modulus of elasticity of their springs and the momentum of their moving parts and supports, while Robinson's anemometers may give a maximum velocity due to small eddies, which

$$
\text { Ver. } x \mathrm{xx},-\mathrm{N} J \cdot 172
$$

is much in excess of the true value. Mr. John Dixon in his letter to the Times on the subject gives a good illustration of a pressure of 80 lbs, to the square foot by comparing it to the weight on the floor of a densely-crowded room. It has been ascertained by experiment that the weight of a crowd of persons can attain 80 to 120 lbs. per square foot, the latter figure being reached only when the experiment was made with labourers of above the average stature packed as closely as possible, and the former being commonly taken as the maximum load to which the platform of a bridge can be subjected by a dense mixed crowd. Thus Mr. Dixon remarks, "the? windows of a building certainly have to bear an equal strain with the walls, and I suppose it would be immaterial to the glass whether it was placed vertically or horizontally. A densely packed crowd hardly weighs 80 lbs. per square foot of the space it stands upon. Reduce therefore the theory to common sense; would any one dream of standing on a floor formed of glazed window sashes?" On the whole we rather think not, even if, to make the case analogous, means were taken to distribute the pressure uniformly, and we are forced to the conclusion that either the Bidston Observatory is a very strongly constructed building with window-sashes anct glass of unusual strength, or that the anemometers are. untrustworthy.

Leaving now the question of the maximum pressure of the wind to be decided by meteorologists, there remains to be ascertained what that pressure would have to reach on the banks of the Thames to endanger the existence of the obelisk. Mr. Dixon's assurance has probably set the fears of many at rest; he says: "As to its stability there need be no fear-I30 ibs. of wind-pressure would not upset it. The columns of the Times are not the place to ventilate calculations and figures." We can assure Mr. Dixon that these calculations would be of sufficient interest to the readers of NATURE to find a place in its columns, but in their absence we are obliged to fall back on our own. The widths of the top and bottom of larger face of the obelisk are respectively 64 inches and 95 inches, the height being 60 feet 6 inches exclusive of the pyramidal point, which would be 7 feet high if intact; assuming, then, an additional foot of height for the lower rounded end, the moment about the base of the pressure on the area of the larger face will be 12,93 I foot pounds for a wind pressure of $1 \mathrm{lb}$. on the square foot. The weight of the stone is estimated at 196 tons, whence, on the assumption of perfect rigidity, the ultimate stability would be 196 tons $x$ radius of base $(2.5)$, and the corresponding wind pressure $=\frac{196 \times 2.5 \times 2240}{12,931}=84.88 \mathrm{lbs}$. per square foot. But the material of the obelisk not being perfectly rigid, it will be seen that this ultimate stability could not be reached. The effect of the wind-pressure is to cause a deviation of the line of action of the resultant pressure on the base from its centre with a diminution of the stress on the windward, and an increase of that on the lee-side of the base; if the decrease exceeds the normal pressure due to the weight the joint will tend to open, while if the increase is carried too far it may reach the crushing strength of the material.

Both these effects have to be considered. Now in the lesign of masonry work of a substantial character it is 
the usual engineering practice to so distribute the stresses that no joint tends to open under the most unfavourable conditions, though this condition is doubtless frequently neglected in flimsy structures. In order that this condition should be fulfilled, the resultant of the pressure on the base must not deviate from the centre of gravity of the base by a quantity greater than $x^{\prime}$ given in the equation $x^{\prime}=\frac{I}{X S}$, where $I$ is the moment of inertia of the base about the neutral axis or line through its centre of gravity perpendicular to the direction of the deviation of the resultant, $S=$ the area of the base, and $X=$ the greatest distance of a point in the base from the neutral axis on the side of the greatest pressure. In the case of a circular base $x^{\prime}=\frac{\text { diameter of base }}{8}=625$ feet in the present instance. The wind pressure corresponding to this deviation $=\frac{196 \times \cdot 625 \times 2240}{12,93 \mathrm{I}}=21 \cdot 22$ lbs. per square foot. When the wind-pressure exceeds this amount there is still the tensile strength of the cement with which the stone is bedded to resist the tendency of the joint to open on the windward side. While the introduction of a layer of cement under the stone doubtiess adds to its steadiness under a wind-pressure of 30 or $50 \mathrm{lbs}$. to the square foot, it would add a very serious element of danger should the pressure ever approach that recorded at the Bidston Observatory, as the cement on the lee side would probably then be subjected to a crushing stress in excess of its strength, and by giving way would cause the column to heel over to some extent; in fact, if there was any probability of that wind-pressure being reached, it would have been safer to have omitted the cement and trusted for the ultimate stability to the far greater resistance to crushing of the granite. It would be impossible, without making assumptions unfounded on experiment, to estimate with any accuracy the value of the additional stability given by the cement in the case of moderate wind-pressures. We have, however, calculated the conditions of equilibrium, neglecting the tensile strength of the cement, as well as the bending of the stone.

On this assumption; we find that a wind pressure of $50 \mathrm{lbs}$, per square foot would cause the joint to open on the windward side as far into the base as the centre; the column would thus be standing only on the leeward half of its base, but the stability would not be endangered by this as the maximum pressure on the base at its outer edge would only amount to 40 tons per square foot, which is less than the crushing strength even of the cement. The line of the resultant pressure on the base would be at a distance of 1472 feet from the centre, if the bending of the column is disregarded. To take into consideration the flexure of the column would involve too long calculations for our present purpose, even if the modulus of elasricity of granite had been determined with sufficient accuracy to make the results of any value, but this we believe has not yet been done. The conclusions we arrive at are as follows:-As long as the foundations remain secure, the obelisk may be frequently subjected to a wind pressure of $2 \mathrm{I}$ lbs. per square foot without the slightest tendency to accident; if subjected at long intervals to a pressure of 40 or 50 lbs. to the square foot, it would probably stand for an indefinitely long period until the fatigue of the cement under variations of stress or its natural decay, if that ever takes place, causes its rupture, but under a pressure of this intensity it must be borne in mind that considerable oscillation would take place, and that if the period of the gusts nearly agreed with the time of vibration of the stone it might be overturned; while if a pressure of 80 lbs. per square foot is reached it is very questionable if the survivors among the inhabitants of the neighbourhood will find it in situ when they have time to go and look for it.

\section{DRAPER'S SCIENTIFIC MEMOIRS}

Scientific Memoirs: being Experimental Contributions to a Knowledge of Radiant Energy. By John William Draper, M.D., LL.D. (London: Sampson, Low, and Co. New York: Harper Brothers, 1878.)

THE scientific world is to be congratulated on the accession to its literature of these memoirs constituting as they do a distinct historical sketch of the works of a physicist who is at once an ardent experimentalist and a careful theorist. As he remarks in his preface, many of his results of experimental investigation on scientific topics have been largely disseminated in European languages, and many of the conclusions they have presented have been admitted into the accepted body of scientific knowledge. The papers in which these results were published have, however, appeared from time to time in various American and English periodicals, but we now have them collected in a form in which they are accessible and convenient for reference.

The four opening memoirs seemingly occupy their position in the volume for the purpose of calling the attention of the reader to the fact that a large portion of the subject that Kirchhoff treated mathematically in a paper which appeared in Poggendorff's Annalen in 1860, and which at the time was considered the foundation of spectrum analysis, had already been experimentally proved and published by our author some thirteen years before. The theorist apparently ignored the work of the experimentalist, and the claim of the one to priority in regard to the enunciation of certain fundamental principles of spectrum analysis is now on the best of evidence disputed by the other. The titles of these first four memoirs and their dates of original publication will give an idea of the indictment framed against Kirchhoff which appears in a note appended to the last of them. They are-

I. Examination of the radiations of red-hot bodies. The production of light by heat, published in 1847 .

II. Spectrum analysis of flames. Production of light by chemical action, published in 1848 .

III. On invisible fixed lines in the sun's spectrum detected by photography, published in 1843 .

IV. On the nature of flame, and on the condition of the sun's surface, published in 1858 .

Controversy regarding priority of discovery is always distasteful, and the indictment against Kirchhoff is a beavy one, but the offence might have been charged also against those scientific writers who, careless of history, have been accomplices in doing Draper an injustice. But turning to the more agreeable side of the subject of these memoirs we find that Draper fixed the temperature at which solid 